\title{
Regarding to the Article 'Effect of Lumbar Stabilization and Dynamic Lumbar Strengthening Exercises in Patients With Chronic Low Back Pain'
}

\author{
James Steele, PhD
}

Centre for Health, Exercise and Sport Science, Southampton Solent University, Southampton, United Kingdom

\section{Dear Editor}

I read the article entitled "Effect of Lumbar Stabilization and Dynamic Lumbar Strengthening Exercises in Patients With Chronic Low Back Pain" by Moon et al. [1] with interest. However, I would like to offer some comments regarding its results and methodology reported.

Moon et al. [1] compared 'Lumbar Stabilization' exercises with 'Dynamic Lumbar Strengthening' exercises. However the exercises pictured for each are very similar (i.e., both are a selection of floor- and ball-based exercises). This similarity of training protocols is highlighted by the authors when they stated "Although no formal definition of lumbar stabilization exercises exists, the approach is aimed at improving the neuromuscular control, strength [our emphasis], and endurance of the muscles that are central to maintaining the dynamic spinal and trunk stability." The similarity between what should have

\footnotetext{
Corresponding author: James Steele

Centre for Health, Exercise and Sport Science, Southampton Solent University, East Park Terrace, Southampton, United Kingdom, SO14 0YN Tel: +44-2380-319606, E-mail: james.steele@solent.ac.uk

(c) This is an open-access article distributed under the terms of the Creative Commons Attribution Non-Commercial License (http://creativecommons. org/licenses/by-nc/3.0) which permits unrestricted noncommercial use, distribution, and reproduction in any medium, provided the original work is properly cited.

Copyright $\odot 2014$ by Korean Academy of Rehabilitation Medicine
}

been protocols aimed at different aspects of lumbar spine function (strength OR stabilization) may explain the lack of differences for most outcomes between the two.

Exercises to conditioning lumbar extensor musculature (erector spinae and multifidus) have been recently reviewed [2]. Muscular activation for floor- and ballbased exercises is highly variable between those selected by Moon et al. [1]. In addition, there is little evidence that these exercises offer conditioning effect for these muscles. However, asymptomatic participants were considered in the recent review [2].

The study by Moon et al. [1] suggests that these exercises in both groups may condition the lumbar extensors. However, the recent review [2] reported that isolated lumbar extension (ILEX) training using machines to provide appropriate pelvic restraint may be optimal. In symptomatic participants, Udermann et al. [3] examined the effect of similar exercises as used by Moon et al. [1] using McKenzie techniques in comparison to combined McKenzie and ILEX over a 4-week intervention and reported no significance difference in the improvements of ILEX strength. However, they did note that acute pain relief might explain such findings. Moon et al. [1] utilised a longer intervention (8 weeks). Therefore, it is reasonable to conclude at least some improvement in ILEX strength might be due to lumbar extensors conditioning. In another study by Helmhout et al. [4] who compared ILEX 
to regular physical therapy (PT) which included stability based exercises, it was reported that similar significant increases in ILEX strength were found in both groups after treatment as well as after 6 and 12 months follow-up. However, in their analysis, they noted that the inclusion of between-group co-interventions (i.e., some of the PT group accidently utilised the ILEX device) might have affected the results. In contrast, Smith et al. [5] conducted a randomised controlled trial and compared exercise using an ILEX device with and without pelvic restraints. Their results showed that only training with the use of restraints (i.e., ILEX) improved ILEX strength, pain, and disability. The authors explained that the use of pejorative terms regarding the unrestrained condition were avoided and participants were informed that the researchers did not know which training would be most effective (hence the purpose of the study, 2012 personal communication from D. Smith; unreferenced). This has been noted as a potentially confounding factor in another study [6], considering the potentially confounding effect of instruction upon outcomes might have helped avoid 'nocebo' effects in the unrestrained group [7]. Thus, these results likely represent the effects of ILEX upon the lumbar extensors as opposed to a placebo effect. This suggests that, although other studies demonstrate benefit in clinical outcomes from any kind of active rehabilitation, the greatest benefits may be achieved from specific ILEX training. Indeed, a recent research study also reported improvements in ILEX strength after an ILEX intervention correlated with improved pain and disability [8].

Recent review [2] suggests that the exercises chosen by Moon et al. [1] could provide poor effect of lumbar extensor conditioning in asymptomatic participants. However, ILEX might be the most effective one. It will be of interest to compare these two approaches. Moon et al. [1] had access to a machine allowing ILEX to be performed (and was used to test ILEX strength as an outcome measure). Thus, a better comparison may have been to include a group performing ILEX exercise using this machine.

There is evidently contrasting evidence in this regard. Much is still to be learnt about the 'black box' of mechanisms with which exercise exerts positive effects on those suffering from chronic low back pain [9]. The present letter highlights a number of questions that still require further clarification: 1) Can exercise other than ILEX condition the lumbar extensors (e.g., improve ILEX strength) in symptomatic participants? 2) Does ILEX provide greater improvements in ILEX strength, pain, and disability than other exercise in symptomatic participants? and 3) Is there indeed any relationship between improved ILEX strength as a result of exercise interventions and changes in pain and disability?

\section{REFERENCES}

1. Moon HJ, Choi KH, Kim DH, Kim HJ, Cho YK, Lee KH, et al. Effect of lumbar stabilization and dynamic lumbar strengthening exercises in patients with chronic low back pain. Ann Rehabil Med 2013;37:110-7.

2. Steele J, Bruce-Low S, Smith D. A review of the specificity of exercises designed for conditioning the lumbar extensors. Br J Sports Med 2013 Oct 3 [Epub]. http://dx.doi.org/10.1136/bjsports-2013-092197.

3. Udermann BE, Mayer JM, Donelson RG, Graves JE, Murray SR. Combining lumbar extension training with McKenzie therapy: effects on pain, disability, and psychosocial functioning in chronic low back pain patients. Gundersen Lutheran Med J 2004;3:7-12.

4. Helmhout PH, Harts CC, Viechtbauer W, Staal JB, de Bie RA. Isolated lumbar extensor strengthening versus regular physical therapy in an army working population with nonacute low back pain: a randomized controlled trial. Arch Phys Med Rehabil 2008;89:1675-85.

5. Smith D, Bissell G, Bruce-Low S, Wakefield C. The effect of lumbar extension training with and without pelvic stabilization on lumbar strength and low back pain. J Back Musculoskelet Rehabil 2011;24:241-9.

6. Steiger F, Wirth B, de Bruin ED, Mannion AF. Answer to the Letter to the Editor of J. Steele et al. concerning manuscript "Is a positive clinical outcome after exercise therapy for chronic non-specific low back pain contingent upon a corresponding improvement in targeted aspects(s) of performance? A systematic review". Eur Spine J 21(4):575-598, by F. Steiger, B. Wirth, E.D. de Bruin, A.F. Mannion (2012). Eur Spine J 2012;21:1888-9.

7. Helmhout PH, Harts CC, Staal JB, de Bie RA. Rationale and design of a multicenter randomized controlled trial on a 'minimal intervention' in Dutch army personnel with nonspecific low back pain [ISRCTN19334317]. BMC Musculoskelet Disord 2004;5(1):40. 
8. Steele J, Bruce-Low S, Smith D, Jessop D, Osborne N. A randomized controlled trial of limited range of motion lumbar extension exercise in chronic low back pain. Spine (Phila Pa 1976) 2013;38:1245-52.

9. Helmhout PH, Staal JB, Maher CG, Petersen T, Rain- ville J, Shaw WS. Exercise therapy and low back pain: insights and proposals to improve the design, conduct, and reporting of clinical trials. Spine (Phila Pa 1976) 2008;33:1782-8. 